E QUEM CURA? AS TRADUÇ NEGOCIADAS EN PROFISSION DE SAÚDE NÃO INDÍGEN, INDÍGENAS NO MÉDIO XII 


\section{QUEM PREVINE E QUEM CURA? AS TRADUÇÕES NEGOCIADAS ENTRE PROFISSIONAIS DE SAÚDE NÃO INDÍGENAS E INDÍGENAS NO MÉDIO XINGU}

\section{KA R I N E A S S UM P Ç Ã O}




\title{
QUEM PREVINE E QUEM CURA? AS TRADUÇÕES NEGOCIA- DAS ENTRE PROFISSIONAIS DE SAÚDE NÃO INDÍGENAS E INDÍGENAS NO MÉDIO XINGU
}

\section{Resumo}

Neste artigo, convido-os a refletir sobre as relações em saúde com base em duas situações ocorridas no médio Xingu, no centro-oeste do Brasil, entre os anos de 2012 e 2013, período em que realizei minha pesquisa de campo junto ao Projeto Xingu, um programa de extensão do Departamento de Medicina Preventiva da Escola Paulista de Medicina (Universidade Federal de São Paulo), que atua na região desde 1965. O intuito é pensar, de forma multidimensional, as relações que dariam vida à chamada "atenção diferenciada", preconizada pela Segunda Conferência Nacional de Saúde Indígena, de 1993, e reafirmada na Política Nacional de Atenção à Saúde dos Povos Indígenas, de 2002, e pela Secretaria Especial de Saúde Indígena, criada em 2010. O intuito deste texto é contribuir para o debate sobre as possibilidades e limites deste princípio visto em situação e a partir do surgimento das chamadas traduções negociadas de cura.

Palavras-chave: Intermedicalidade, Atenção diferenciada, traduções negociadas de cura

\section{WHO PREVENTS AND WHO HEALS? THE NEGOTIATED TRANSLATIONS BETWEEN NON-INDIGENOUS HEALTH PRO- FESSIONALS AND INDIGENOUS IN THE MIDDLE XINGU}

\begin{abstract}
In this manuscript, I invite you to reflect on health relationships based on two situations that occurred in the middle Xingu, in the center-west of Brazil, between the years of 2012 and 2013, during which time I conducted my field research with the Xingu Project, an extension program of the Department of Preventive Medicine of São Paulo Medical School (Federal University of São Paulo), which has been operating in the region since 1965. The intention is to think, in a multidimensional way, the relationships that would bring to life the so-called "differentiated attention" recommended by the Second National Conference on Indigenous Health, in 1993, and reaffirmed in the National Policy on Attention to
\end{abstract}


Indigenous Peoples Health, of 2002, and by the Special Secretariat of Indigenous Health, created in 2010. The purpose of this manuscript is to contribute to the debate about the possibilities and limits of this principle seen in loco and from the appearance of the so-called negotiated healing translations.

Keywords: Intermedicality, differentiated attention, negotiated healing translations.

\section{¿QUIÉN PREVIENE Y QUIÉN CURA? LAS TRADUCCIONES NEGOCIADAS ENTRE PROFESIONALES DE LA SALUD NO IN- DÍGENAS E INDÍGENAS EN EL MEDIO XINGÚ}

\section{Resumen}

En este artículo los invito a reflexionar sobre las relaciones en salud con base en dos situaciones ocurridas en el medio Xingú, en el centro-oeste brasilero, entre los años de 2012 y 2013, periodo en que realicé mi investigación de campo junto al Proyecto Xingú, un programa de extensión del Departamento de Medicina Preventiva de la Escuela Paulista de Medicina (Universidad Federal de São Paulo), que actúa en la región desde 1965. La intención es pensar, de forma multidimensional las relaciones que darían vida a la llamada "atención diferenciada", declarada en la Segunda Conferencia Nacional de Salud Indígena, de 1993, y reafirmada en la Política Nacional de Atención a la Salud de los Pueblos Indígenas de 2002 por la Secretaría Especial de Salud Indígena, creada en 2010. La intención de este texto es contribuir al debate sobre las posibilidades y límites de este principio, puesto en situación a partir del surgimiento de las llamadas traducciones negociadas de cura.

Palabras clave: Intermedicina; Atención diferenciada; Traducciones negociadas de cura.

Karine Assumpção*

karine.assumpcao@gmail.com 


\section{INTRODUÇÃO}

Situação 1: Certa vez, participei de uma ação de promoção de saúde em uma aldeia Kawaiwete ${ }^{2}$, localizada na região central da Terra indígena Xingu (TIX), conhecida como Médio Xingu. Durante a ação, que foi organizada a partir de um pedido de acompanhamento da saúde dos kawaiwete feito por estes indígenas ao Projeto Xingu ${ }^{3}$ conversávamos com um casal sobre a situação de desnutrição e anemia diagnosticadas em seu filho. Em meio a desenhos de sol e lua rabiscados em um papel por uma das nutricionistas, denotando os vários momentos do dia em que é preciso garantir que a criança coma, era nítido o semblante preocupado do casal, não tanto por alimentar seu filho de forma inadequada, mas porque não respeitaram certas restrições culturais para pais de recém-nascidos e a moça gestava outro bebê. Assim, por mais que os médicos falassem que dar o sulfato ferroso iria ajudá-lo e que, se eles cuidassem melhor dos horários de alimentação do menino, ele se recuperaria, a feição de ambos continuava negativa, representando a incredulidade quanto à reversão da transgressão cometida a partir de tais medidas. Ao término do diálogo, o rapaz informou que começaria o tratamento com o pajé ${ }^{4}$, que curara várias crianças com o mesmo problema, não fazia muito tempo.

Situação 2: Outra vez, enquanto realizávamos viagens pelas aldeias do médio Xingu com a finalidade de vacinar e acompanhar as pessoas diagnosticadas com doenças crônicas, presenciei o diálogo com um jovem trumai que tinha pressão alta e que decidiu parar com a medicação biomédica, mesmo sem enfrentar problemas para obtê-la, o que acontece frequentemente em locais de difícil acesso, como me informou uma enfermeira. O jovem passara a se tratar com um pajé e com ervas. Quando o médico não indígena verificou que ele estava há sete meses sem os medicamentos, alertou o rapaz dos riscos que corria e de que passaria o caso para os médicos mais experientes, que o orientavam nessas que eram suas primeiras atuações em aldeias, para saber se o jovem realmente poderia ficar sem o remédio.

Situações como essas fazem parte da "intermedicalidade" (Foller 2004) e perpassam o universo do Subsistema de Saúde Indígena do Sistema Único de Saúde do Brasil (SASISUS), criado em 1999, pela lei no 9863 , e gerido desde 2010 pela Secretaria Especial de Saúde Indígena (SESAI) ${ }^{5}$.

O SASISUS atualmente está organizado em 34 Distritos Sanitários Especiais Indígenas (DSEI) que são unidades gestoras descentralizadas, sendo os povos atendidos e a região de intervenção definidas por critérios socioculturais, geográficos, epidemiológicos e de acesso aos serviços (Garnelo \& Sampaio 2005) 6 . Nesse "modelo de atenção diferenciada", como é descrito na Política Nacional de Atenção à Saúde dos Povos Indígenas (PNASPI), de 2002, as unidades de atendimento de saúde presentes em aldeias - e geridas pelos distritos - realizam a chamada atenção primária de saúde e, quando avaliam ser necessário, transferem os doentes para outras instituições do SUS, que ofereçam atenção secundária e/ou terciária. 
$\mathrm{Na}$ PNASPI também estão enumerados alguns princípios norteadores para a execução dos trabalhos no SASISUS e menciona que para a efetivação desses,

É necessário que a atenção à saúde se dê de forma diferenciada, levando-se em consideração as especificidades culturais, epidemiológicas e operacionais desses povos. Assim, dever-se-á desenvolver e fazer uso de tecnologias apropriadas por meio da adequação das formas ocidentais convencionais de organização de serviços (Brasil-PNASPI 2002: 6).

Porém, como Cardoso (2015) observa, se há uma pressuposição da noção de "atenção diferenciada" como condição para a construção de um modelo assistencial inclusivo, paralelamente há muitas vezes uma forma normativa de operacionalizá-lo. É como se a primeira parte do trecho acima citado estivesse desassociado do segundo.

Neste artigo, portanto, reflito sobre duas situações, relatadas no início deste texto, ocorridas entre os anos de 2012 e 2013 na região de abrangência do DSEI Xingu, que inclui a Terra Indígena Xingu e Wawi e aldeias de 16 povos indígenas ${ }^{7}$. Elas se sucederam quando eu acompanhava as ações do Projeto Xingu, programa de extensão do departamento de medicina preventiva da Universidade Federal de São Paulo, existente desde 1965 e que está presente prioritariamente na TIX (Baruzzi \& Junqueira 2005). Por muitos anos, o Projeto foi gestor de uma parte considerável dos recursos do DSEI Xingu e atualmente realiza a vacinação e inter- venções pontuais na região. Com isso, os membros há mais tempo no projeto, e que fizeram parte das discussões de criação do subsistema, acumularam uma práxis médica (Campos 1997) singular, e repassam para os novatos determinadas sínteses históricas construídas com os povos com os quais se relacionam (Assumpção 2014). Tais sínteses perpassam as situações 1 e 2 , que analisaremos a seguir.

Trago essas situações não para avaliá-las ou descrevê-las em sua totalidade, mas por considerá-las boas para pensar, de forma multidimensional, as relações que dariam vida à chamada "atenção diferenciada". Assim, o intuito deste texto seria contribuir para o debate sobre as possibilidades e limites desse modelo diferenciado e do que proponho chamar de traduções negociadas de cura, que acentuam o caráter político dessas relações.

\section{DESNUTRINDO O SULFATO FER- ROSO}

Questões de saúde relacionadas à criança indígena requerem uma análise específica, que irei apenas pincelar para ajudar-nos a enxergar uma das dimensões presentes na primeira situação relatada neste artigo. Para muitos povos, e para os kawaiwete em específico, os exames que acusam a desnutrição de uma criança acusam, ao mesmo tempo, uma vingança contra os pais dela. Principalmente nos primeiros meses e anos de vida, algumas atitudes dos pais reverberam no futuro do filho, e por isso essa fase é marcada por restrições (caça, alimentação, relação sexual 
etc.) que, caso não sejam respeitadas, repercutem no adoecimento da criança (Grünberg 2004: 173-84).

Assim, os estudos ameríndios mostram que não é possível focar em aspectos que se atenham ao corpo "físico" - que nesse caso seria o corpo desnutrido da criança, desconsiderando o que para a sociedade moderna seria a "alma" e para os ameríndios seria a pessoa. Como Rivière (1974) observa, o Couvade, relacionado à criação ou nutrição espiritual do recém-nascido pelo pais, é um dos caminhos encontrados por diversos povos indígenas, como os Waiwai e os Urubu ${ }^{8}$, para lidar com a problemática da fabricação de pessoas. Isso porque, para os povos das terras baixas da América do Sul, o corpo, e sua fabricação, decoração, transformação e destruição, seria um organizador social central. Logo, os cuidados com "os fluidos corporais" e "os processos de comunicação do corpo com o mundo" diferenciariam a sócio-lógica das sociedades sul-americanas de outras (Seeger et al. 1979).

Desde Mauss (1973) sabemos que a noção de pessoa é uma categoria fundada na experiência social, ou seja, uma construção coletiva que oferece um significado ao vivido. Assim, a ideia de uma pessoa como fenômeno natural/ biológico está inserida no imaginário ocidental contemporâneo, sustentado pela biomedicina (Le Breton 2011), tanto quanto a sócio-lógica da construção da pessoa ameríndia está apoiada em uma fisio-lógica da fabricação de seus corpos, o que torna a pessoa e o corpo entidades simbólicas e não cindidas (Seeger et al. 1979). Assim, noções diferentes de pessoa e corpo influenciam diretamente o reconhecimento de certos sintomas como uma "doença” (Langdon 2005), algo a ser tratado, bem como os diagnósticos possíveis (aceitáveis), a escolha e a avaliação do tratamento, gerando situações "patológicas" e itinerários terapêuticos variados para se chegar ao mesmo fim: a cura (Duarte 2003).

No caso apresentado neste artigo como "situação 1", as profissionais da saúde, seguindo seus pressupostos biomédicos, explicavam que a desnutrição da criança estaria relacionada com sua má alimentação, ou devido à ingestão de alimentos inapropriados para pessoas dessa faixa etária, e indicavam o xarope de sulfato ferroso como uma das medidas imprescindíveis para a melhora do menino. A solução apontada pelos pais dele, entretanto, era buscar o tratamento com o pajé, que conhece raízes que fazem a criança ter vontade de comer e engordar e, paralelamente a esse cuidado, também considera tratar as transgressões cometidas pelos pais como parte do processo de cura do filho. Logo, as intervenções do pajé podem afetar outros corpos, produzindo efeitos (o desejo de comer) nesses corpos, modificando as possíveis consequências indesejáveis (Vilaça 2000, Kopenawa \& Albert 2015).

O que está em jogo nesse desencontro de opiniões sobre a solução para o efeito são concepções distintas sobre a causa do problema. Para abordarmos tal diferença é preciso considerar que nessa situação, além da criança, seus pais, os profissionais de saúde e o pajé, há outros agentes igualmente 
envolvidos, como o sulfato ferroso e as raízes que fazem crianças engordarem. Pensando criticamente no conceito de agência, faz-se importante examinar como as noções de agência (conhecimento e capacidade) são constituídas e como afetam o gerenciamento das relações e dos efeitos que os agentes podem gerar uns com relação aos outros (Strathern 2006).

Seguindo o esquema conceitual moderno, a desnutrição e anemia infantil estariam relacionadas à falta de nutrientes adequados, geralmente se manifestando juntamente com um quadro de diarreias. Ao mesmo tempo, o sulfato ferroso, substância comumente prescrita pelos médicos nesses casos, pode também causar diarreia. Sua versão xarope, distribuída em maior quantidade para as farmácias dos polos de saúde existentes nas aldeias da região, tem um gosto forte, que pode fazer a criança não querer comer após a ingestão. Com isso, durante nossa estadia na aldeia, muitas foram as falas das e dos kawaiwete contra esse medicamento e em apoio ao tratamento do pajé, visto que o sulfato ferroso, associado às intervenções biomédicas, muitas vezes provoca mais diarreia no corpo que consideram necessitar de outro efeito.

Quando esse tipo de constatação era levantado por algum kawaiwete nas falas públicas, os médicos não a contestavam, reforçando a importância do tratamento com o pajé. As recomendações de sulfato ferroso, entretanto, continuaram sendo feitas pelos médicos que participavam da ação, durante conversas com outras famílias ou nas consultas, após a leitura de algum exa- me. Quando conversávamos a respeito, eles reconheciam os efeitos colaterais do remédio e pensavam em tentar consegui-lo em comprimido - que na concepção deles diminuiria o efeito colateral do gosto desagradável. Todavia, eles não consideravam alternativas para prevenirem casos de anemia mais graves se não, naquelas condições, receitá-lo.

Em situações como esta, o respeito ao "Outro" exprimia-se em não contrariá-lo, ao menos no discurso ou argumento, mas seguir tentando negociar o uso do sulfato ferroso. Isso porque as divergências de práticas medicinais ocorrem conforme o modo como a eficácia das práticas de $\operatorname{cura}^{9}$ é interpretada pelos sujeitos, estando diretamente relacionada às suas construções histórico-sociais sobre saúde/doença/cura ${ }^{10}$, como exemplificaremos uma vez mais no segundo caso.

\section{A PRESSÃO PARA SE OBTER ALTA}

Com relação ao segundo caso relatado, envolvendo um jovem trumai diagnosticado com pressão alta e que decidiu parar com a medicação biomédica, haviam três medições de sua pressão registradas em seu prontuário, sendo duas realizadas durante os mencionados sete meses de não utilização do remédio, todas com resultados dentro da "normalidade" $"$.

A menção sobre o tratamento do pajé, assim como na situação 1 , não gerou uma contestação direta do médico não indígena quanto à possibilidade desse tratamento ser eficaz, mas também não gerou curiosidade sobre as plantas 
(nome, características, modo de preparo etc.) ou sobre as ações engendradas pelo pajé. Ou seja, o profissional não indígena não mostrou surpresa com o fato do pajé e suas ervas estarem controlando a pressão do rapaz. Com base no trabalho de campo realizado e bibliografia do tema (Gallois 1991, Foller 2004), essa (não)reação estaria relacionada à incoerência, para aquele médico, de um caso de pressão alta ser lido através da chave "doença de índio" - e, portanto, tratável pelo pajé. Visto ser um dos males trazidos pela nossa sociedade aos indígenas, como dizia, a pressão alta não seria como as "doenças de reclusão" - que esse médico estudava na época - que podem acometer os jovens alto xinguanos durante seus rituais de passagem, situação em que se faz uma relação direta do uso de raízes com o estado de liminaridade da pessoa. Detenhamo-nos na agência dessas raízes.

A associação dos efeitos maléficos das raízes à dieta é parte constitutiva da explicação alto xinguana sobre a doença de reclusão. Segundo Verani (1990), eles argumentam que a reclusão púbere está associada a uma série de proibições concernentes à dieta e atividade sexual, que se referem ao aspecto moral, assim como o aprendizado de artes e técnicas necessárias à formação de um adulto aproximado à personalidade ideal. As raízes são "venenosas" pois têm por patrono (“dono") um espírito que, aborrecido com o comportamento do adolescente recluso, pode causar-lhe a paralisia (1990: 29). Logo, por que considerar a possibilidade de agência dessas raízes e não de outras?
A conversa terminou com o profissional de saúde dizendo que, provavelmente, a decisão do jovem não traria maiores problemas, já que sua pressão estava controlada. Ao mesmo tempo, avisou que, se um médico há mais tempo no Projeto confirmasse a necessidade do uso, ele teria que voltar a tomar o remédio. O jovem escutou-o e saiu.

Assim, ao longo dos estudos de campo do mestrado (Assumpção 2014) observei que há determinadas doenças crônicas e degenerativas, como a hipertensão, obesidade e diabetes que ampliam o poder do discurso de intervenção e controle da biomedicina frente às pessoas diagnosticadas como possuidores desses males em seus corpos. Isso porque essas seriam doenças cuja não existência de cura biomédica, e uma perspectiva de debilidades graves e letais decorrentes de sua evolução, acionaria diversos tratamentos preventivos e prescritivos criados pela biomedicina para controlar o problema.

No caso do Xingu, o Projeto Xingu acompanha o histórico de diagnósticos dessas doenças e relata que em 1986, quando participaram de um estudo mundial sobre pressão arterial, "não foi constatado nenhum caso de hipertensão arterial, obesidade ou diabetes mellitus entre os xinguanos" (2009: 58). Porém, em 2009, estariam em acompanhamento 47 hipertensos e 4 portadores de diabetes mellitus na área de abrangência do baixo, médio e leste Xingu (Ibidem: 60). O aumento de diagnósticos biomédicos dessas doenças tem gerado uma mobilização das lideranças, pajés e população no sentido de entender melhor o problema 
descrito pelos não indígenas. Buscam-se caminhos para explicar e enfrentar esses males, como na ação de promoção de saúde, na aldeia Kawaiwete, e o pajé que estava tratando o jovem trumai.

Porém, a etiologia indígena - se é que podemos chamar assim, uma vez que são os agentes, humanos ou não, que serão nomeados e suas ações que serão descritas, e não as doenças - não corresponde necessariamente a da biomedicina. As situações em que as pessoas ficam doentes são frutos de agenciamentos e socialidades distintas (Tavares 2017, Strathern 2014), sendo que as "doenças" acima descritas, assim como outras, não necessariamente serão nomeadas e categorizadas de forma similar ou correlata às classificações biomédicas, podendo não serem consideradas "doenças de branco", possuírem outras causas e, portanto, serem tratadas e curadas pelos pajés.

\section{QUEM PREVINE E QUEM CURA, OU SOBRE UMA TRADUÇÃO NEGO- CIADA}

Observo que a afirmação do poder de resolução do pajé ocorre mais frequentemente quando as prevenções sugeridas pelos biomédicos adentram a organização social do grupo. No caso do jovem acima relatado, a conversa mobilizou diferentes concepções de cura, envolvendo diferentes concepções sobre o que é doença. Seguindo os pressupostos biomédicos presentes nos discursos da situação 1 e 2 , a prevenção das doenças crônicas só pode ser realizada atualmente interferindose no comportamento das pessoas, e a contenção dessas doenças necessita de cuidados diários, não dependendo das visitas esporádicas dos profissionais de saúde para acontecer.

A negociação do tratamento sairia, portanto, da esfera pública, na qual se costuma lidar com os "brancos", e adentraria a esfera local, onde "as representações sobre a doença não constituem um sistema autônomo, mas fazem parte de um prolongamento social tanto quanto da teoria do Corpo e da Pessoa à qual ela se integra" (Verani 1990: 31), como vimos no subitem anterior. Contudo, como salienta Silveira, Com o acesso à biomedicina facilitado, merece reflexão também o quanto a noção de prevenção de doenças pode ser incompatível com o viver tradicional. Para os Yanomami, nem todas as doenças podem ser prevenidas, já que todos são vulneráveis a agressões xamânicas" (2004: 123).

Evidencia-se, nesses casos, uma contradição relacionada às concepções dos corpos, agências e doenças. O imaginário ocidental moderno, ligado ao surgimento dos anatomistas, que distinguiram o homem de seu corpo, abrindo cadáveres e se deparando com exemplos de "máquinas humanas" (Le Breton 2011: 285) cuja identidade é indiferente, fez com que o corpo se tornasse, genericamente, um "receptáculo de doenças" (Ibidem), ou ainda, um corpo a ser prevenido das doenças. Com esse humano (alma/subjetividade) despregado de seu corpo (matéria), a biomedicina moderna passou a se dedicar ao conhecimento da estrutura e função 
do organismo humano, às causas das doenças, aos métodos de investigação científica e de análise complementar de diagnóstico, além de outros métodos de racionalização biológica.

Ressaltado esse histórico processo de secularização e biologização da medicina moderna, é preciso salientar que ela não é uma entidade ou um constructo homogêneo. Observando-a mais de perto, vê-se sua composição relacional entre diferentes segmentos e escolas de pensamento, os quais estão continuamente presentes nas diferentes práticas médicas e nas relações terapeuta/paciente (Ibidem), com campos críticos em seu próprio interior. Laurell (1982) relaciona, por exemplo, o desenvolvimento do capitalismo com a hegemonia do conceito de doença centrado na biologia individual, o que restringiria o conhecimento que poderia emergir de outras concepções contemporâneas (: 10). Campos (1997) também critica as consequências desse conceito, que geraria uma noção de "Doença total", sequestradora da subjetividade da pessoa doente. Segundo ele, "uma enfermidade perturba, transforma e até mata Sujeitos, contudo, apenas raramente, liquida com todas as demais dimensões da existência de cada um" (: 5).

Contudo, nas relações aqui analisadas, os profissionais da saúde realizam o movimento concomitante de criticar a impessoalidade e rigidez conceitual do modelo biomédico padrão e reproduzir os preceitos deste sistema médico no qual foram formados, pensando em como proteger as pessoas que possuem corpos vulneráveis às doenças (receptáculos) ${ }^{12}$. Nas linhas que se se- guem, refletiremos sobre esse segundo $\operatorname{aspecto}^{13}$.

Ao realizar conversas com os pais de uma criança para aconselhá-los a dar sulfato ferroso para ela, ou com um jovem sobre os riscos de não tomar o remédio industrializado que controla sua pressão alta, os profissionais de saúde procuram preveni-los de problemas mais graves que consideram serem consequências provocadas, dentre outros agravantes, pela falta de tratamento de uma doença. Estas medidas preventivas biomédicas ganhariam mais potência quando as doenças fossem consideradas como "doenças de branco", apesar dos motivos e lógicas pelos quais as doenças são definidas pelos agentes, indígenas e não indígena, como pertencente a essa categoria serem variados. Logo, a potência da prevenção depende do entendimento sobre a doença, como o exemplo do jovem que tratava seu problema com o pajé - será que considerava que estava sofrendo de pressão alta? E se a resposta a primeira questão fosse negativa, qual seria a potência da prevenção que lhe foi proposta? Ele teria mesmo que voltar a tomar o remédio?

Assim, as chamadas desnutrição e pressão alta, como demais doenças crônicas degenerativas, são consideradas pela biomedicina majoritariamente como uma consequência dos maus comportamentos dos sujeitos, dos maus hábitos, tendo como causa questões internas ao indivíduo - por exemplo, a má alimentação e o desgaste de certos órgãos. $\mathrm{O}$ aumento dos diagnósticos dessas doenças no Xingu tem sido associado pelos não indígenas ao maior acesso à 
alimentação industrializada, ou seja, às comidas do "branco" - além de outros efeitos nocivos provocados por este, como o desmatamento, poluição dos rios etc. Sendo assim, essas doenças são classificadas pelos profissionais de saúde como "doença de branco", uma vez que cabe a eles agir, prevenir os indígenas dos malefícios da sociedade ocidental e/ou mostrar-lhes a melhor forma de consumir esses produtos - ou seja, uma forma menos maléfica e mais consciente de comprá-los, prepará-los e consumi-los. Ao mesmo tempo, considerar essas doenças como "doença de branco", por exemplo, acarretam avaliações biomédicas dos níveis de gordura e açúcar do corpo dos indígenas para preveni-los das consequências de graus avançados dessas doenças.

As coisas são encaminhadas, assim, como se a biomedicina e seus representantes detivessem um poder de prevenção e que, a partir da justificativa de que algumas doenças foram trazidas pela intensificação do contato com os não indígenas e suas formas de viver, comer e se comportar, essas seriam "doenças de branco" e, portanto, seriam os não indígenas que deveriam amenizar o problema, tendo uma dívida histórica de arrumar o que desajeitaram. Portanto, para muitos dos profissionais de saúde não indígenas com os quais trabalhei, há uma clara separação entre o antes e o depois do contato dos brancos com os indígenas que fez "surgir" doenças antes inexistentes: "é preciso desenvolver ações no nível da atenção básica que minimizem o impacto sanitário negativo advindo do contato dos índios com a sociedade nacional" (Pro- jeto Xingu 2013). Já para muitos dos povos indígenas, e para os xinguanos pelo que observei em campo e em conversas -, a explicação para o aparecimento de infortúnios e/ou fatalidades (mortes) estaria situada para além dos sintomas físicos, ou do que é biomedicamente comprovado, com cada caso sendo avaliado conforme a pessoa. Assim, é possível notar que o que ocorre é a inclusão da causa "contato com os brancos" no repertório de explicações indígenas (Gallois 1991) - uma causa potente, mas não cronológica.

As práticas biomédicas seriam ressignificadas ao adentrarem no cotidiano indígena e seu universo, muitas vezes sendo aceitas, por exemplo, pelo alívio rápido que proporcionam. Esse uso é definido por Langdon (1988) como pouco modificador do objetivo central dos povos indígenas de entender e reverter as causas ocultas $\mathrm{da}$ enfermidade que os atinge. Isso porque, ao mesmo tempo em que utilizam as práticas biomédicas, procuram em eventos passados "rupturas sociais, políticas ou metafísicas que subjazam à doença" (: 257), como as mencionadas pelos país da criança da situação 1. Segundo a autora, os indígenas vêm demonstrando que é possível "absorver" o que lhes convém das práticas biomédicas sem negar sua própria medicina, mantendo a autoridade e a eficácia curativa desta (Langdon 2005). Há, contudo, uma outra forma de traduzir: menos como uma facilidade de absorção do novo e mais como uma continuidade lógica do entendimento de situações de saúde/doença/cura. 
Por exemplo, a noção de "doença-punição" - ou vingança, em uma tradução mais próxima do mundo ameríndio de agencias em disputa, com possibilidade de reversibilidade entre agressor e agredido (Viveiros de Castro 2004) -, na qual "a doença é vista como a consequência necessária do que o próprio indivíduo ou o próprio grupo provocou" (Laplantine 1986:228), faria parte da pluralidade causal de males concebidos pelos povos do baixo, médio e leste Xingu (Junqueira 2005; Grünberg 2004; Seeger 1980; Lima 2005). Essa possível causa de adoecimento seria anterior ao tempo em que os profissionais de saúde começaram a discutir sobre as "doenças de branco" na TIX. Esses males não seriam novidade, e os pajés os "diagnosticariam" e cuidariam, como no caso do casal agredido pela desnutrição do filho.

Em seus estudos junto aos Waiãpi, Gallois (1991), pesquisando o "surgimento" de doenças pós-contato, pergunta-se sobre o real significado do termo "doença de branco", muitas vezes usado de maneira equivoca$\mathrm{da}$ por diversos profissionais - entre eles, os antropólogos. Segundo a autora, esta categoria surge das definições e discursos dos não indígenas envolvidos com a saúde indígena, que justificam suas intervenções na área da saúde com objetivos salvacionistas, alegando que estes se consideram impotentes diante das "doenças de branco" (: 177). No entanto, para os Waiãpi, o termo "doença de branco" não designa todas as doenças surgidas após o contato, como na definição não indígena, estando presen- te na pluralidade causal do sistema médico indígena.

Por isso, Gallois considera o uso indiscriminado da categoria "doença de branco" por aqueles que não são indígenas como uma confirmação da ideia evolucionista de que a medicina mais "racional" e científica deveria substituir a "irracional" e mais tradicional. Para ela, a categoria "doença de branco" não foi introduzida recentemente no sistema waiãpi de explicação da doença, tendo sido integrada como parte de seu sistema etiológico por conter teorias do contágio e doença relacionadas à aproximação de povos distantes, sendo as intervenções médicas dos "brancos" vistas muito mais como opção terapêutica do que explicação causal. Portanto, as incorporações de práticas biomédicas não substituiriam os sistemas etiológicos tradicionais, uma vez que estas práticas seriam habitualmente incorporadas na esfera dos efeitos e não das causas (:200).

No caso do Xingu, Cardoso (2004) confere o surgimento das categorias "doença de branco" e "doença de índio" aos indígenas e a ressignificação dessas categorias aos não indígenas, pois

A primeira [categoria], usada pela população local [indígena] para se referir às doenças que os índios "pegaram" ou "pegam" no contato com os "brancos" (principalmente doenças viróticas e infecto-contagiosas), tem sido re-designada como doença "física/orgânica" e, portanto, sujeita à competência da "medicina dos brancos"; a segunda, utilizada pela população local para se referir às doenças ou sintoma- 
tologias reconhecidas no sistema classificatório e terapêutico nativo, em "doença espiritual", sujeita, pois, ao tratamento performatizado por pajés ou outros especialistas terapêuticos locais (Cardoso 2004: 163).

E assim, considerando a continuidade lógica do entendimento de situações de saúde/doença/cura pelos agentes, é possível esboçar uma interpretação política dessas permanências ou "não substituição", uma vez que parto da concepção de Sahlins de que não existem permanências sem transformações, e vice versa, em relações como as descritas. Com base nas situações que vivenciei em campo, é possível afirmar que a "autoridade e eficácia curativa da medicina indígena" - em sentido amplo, e do pajé nas situações descritas neste artigo - teria se tornado uma tradução ${ }^{14}$ negociada na relação entre os profissionais de saúde próximos ao Projeto Xingu e os indígenas do baixo, médio e leste Xingu, e estenderia o entendimento dessa tradução como uma ampliação possível da noção de "equivocação controlada" formulada por Viveiros de Castro (2004). Segundo o autor, a "equivocação controlada" seria o tipo de tradução presente no perspectivismo ameríndio, no qual a "equivocação" seria um modo de comunicação entre diferentes posições de perspectiva, e "controlado" como algo que se equilibra sob uma linha tênue entre manter sua consciência ou tê-la capturada pelo outro (Ibidem). Vejamos como isso se relaciona com a tradução mencionada.
$\mathrm{Na}$ manipulação do que chamo de tradução negociada, a autoridade da medicina indígena seria potencializada pela quantidade elevada de curas realizadas pelos pajés em pessoas visivelmente fora de seu estado "normal" em comparação à biomedicina, que muitas vezes tratará o enfermo em algum momento de seu itinerário terapêutico, mas não dirá que realizou a cura. Muito pelo contrário, é comum os médicos alertarem seus pacientes de que en vou te receitar dipirona, mas provavelmente essa dor vai voltar enquanto você não melhorar seus bábitos, ou vou aplicar essa injeção aqui, mas daqui a três meses vamos ter que fažer nova aplicação, porque esses sintomas vão voltar, não correspondendo necessariamente à uma cura.

Às vezes, uma situação que seria classificada pelos agentes biomédicos como um episódio de uma doença mais grave, que não cessará com o término do quadro agudo, será agenciada pelo pajé como um processo de cura. E, caso ocorram novas situações de doença ligadas à situação anterior (envolvendo as mesmas pessoas ou grupo, por exemplo), curas diversas poderão ser realizadas pelo pajé, ou haver reavaliação do "diagnóstico" anteriormente dado quantas vezes isso se mostrar coerente com a lógica desse processo. Existem mudanças de diagnósticos na prática biomédica, quando se investiga um caso e se busca, por exemplo, um diagnóstico preciso, mas no caso dos pajés, as mudanças estão relacionadas aos nexos causais implicados no adoecimento, advindos muitas vezes de múltiplos agentes que se revelam du- 
rante suas investidas de tradução da situação (Carneiro da Cunha, 1998).

Nesses momentos, nos cabe perguntar: essas curas não seriam curas? $O$ pajé curaria somente algumas doenças e sintomas, pois a cura de fato só ocorre quando se aniquila por completo determinada manifestação perturbadora ao estado de bem-estar do indivíduo? Imaginemos uma situação hipotética na qual desconsideraremos regras oficiais vigentes sobre o exercício da prática biomédica atual ${ }^{15}$ para pensarmos qual dessas situações se aproximaria mais do objetivo último propagado pelos órgãos biomédicos de que "a saúde é um estado de completo bem-estar físico, mental e social, e não consiste apenas na ausência de doença ou de enfermidade" (Organização Mundial da Saúde 1978): processos sucessivos de cura ou tratamentos de sintomas de doenças "sem fim"?

É devido a essas disparidades lógico-explicativas existentes entre os sistemas de cura que os agentes envolvidos nessas relações aqui analisadas negociam através de traduções: enquanto os profissionais do Projeto demonstram sua eficácia pela prevenção, os pajés indígenas demonstram-na pela cura. Não que o primeiro também não cure, ou que o segundo não previna, mas no diálogo entre indígenas e Projeto Xingu, não é raro presenciar os não indígenas dizerem eu não curo, quem cura é o pajé, ou um pajé solicitar Gelol para passar na pessoa, após realizar seu trabalho. Isso não os deslegitima nesse contexto, mas sim evidencia o reconhecimento da eficácia dos tratamentos e a possibilidade de uma convivência política entre eles.
Assim, a prevenção biomédica partiria de uma vontade de manter as populações da TIX afastadas dos grandes males que acometem atualmente a sociedade moderna, expressa em frases como queremos preveni-los de nós mesmos e é uma pena que esses problemas estejam começando a surgir no Xingu, ou retardar ao máximo essa contaminação. Mas esse pensamento pode gerar um ímpeto de se sobrepor a ação dos povos indígenas de interpretação, organização, prevenção e tratamento do que eles avaliam como problemas.

Como os Desana descritos por Buchillet (2002), que associaram a varíola e o sarampo às "contas de vidro" que eram trocadas com os brancos nas primeiras fases desse contato, os povos do Baixo, Médio e Leste do Xingu também realizam associações entre certos males e a presença dos não indígenas e / ou objetos trazidos por eles à aldeia, mesmo que fossem utensílios, considerados pelos biomédicos, preventivos, como o sulfato ferroso. Isso, contudo, não é fixado com classificações rígidas, como “doença de branco", que desautorizariam a agência do pajé.

Aliás, parcas são as fronteiras reforçadas por essas populações (Levi-Strauss 1993), que realizam sínteses constantes entre elementos exógenos e os sistemas cognitivos e terapêuticos tradicionais, como quando dizem que são os espíritos que fazem os profissionais de saúde não indígenas fumarem muito, como ocorre com os pajés - visto que ambos, médicos e pajés, são sujeitos envolvidos com processos de cura; ou, ainda, quando uma indígena Kawaiwete diz que o correto seria somente o 
indígena que demonstra dependência alcoólica e sua família se converterem às religiões não indígenas, e não comunidades indígenas inteiras se converterem, realizando, assim, um uso próprio da religião ${ }^{16}$.

Esses elementos exógenos sintetizados pelos indígenas, "longe de invalidar sua lógica e coerência internas, pelo contrário, enriquece-os, contribuindo para reafirmar a validade do universo conceitual indígena" (Buchillet 2002: 129). É assim que a desnutrição e a pressão alta tornam-se, por meio de associações feitas pelos indígenas, traduções negociadas com os não indígenas, que atestam a eficácia dos pajés. Para a desnutrição infantil, existe pajelança e ervas administradas pelo pajé Kawaiwete que fazem menino ter vontade de comer e engordar, considerados sinais de melhora do doente. Para a pressão alta eram administradas ervas e procedimentos apropriados, concomitantemente ao fato de o rapaz diagnosticado como hipertenso estar com a pressão arterial de seu corpo controlada há mais de sete meses.

Essas associações, contudo, não são ditas aos profissionais de saúde não indígenas constantemente nos atendimentos realizados no Xingu. Pelo contrário, são reveladas em determinados eventos de saúde. São em espaços/ eventos - como os Encontros descritos por Kelly (2009) e a Ação de Promoção à Saúde promovida pelo Projeto Xingu nos Kawaiwete - criados para a conversa, o debate e a troca de conhecimentos que essas interpretações são geralmente expostas e agem produzindo sínteses significativas para as relações em saúde indígena. Não por acaso que esses espaços passaram a ser valorizados pelos profissionais do Projeto, que não possuem obrigatoriedades burocráticas para promovê-los. Esses momentos, acrescidos da relação duradoura desses profissionais não indígenas com os xinguanos, criam condições para o compartilhamento de traduções que, ao serem negociadas e sua negociação se consolidar, possibilitam a existência de um acordo político. Isso reforça a ideia de que traduções como eu não curo, quem cura é o pajé seriam parte da dimensão política da relação em saúde indígena, e não sinais do surgimento de uma concepção/ conceituação compartilhada, isenta de equívocos - controlados (Viveiros de Castro 2004) ou não controlados (Kelly 2009).

Ou seja, não estaríamos diante da falta de consciência dos equívocos, o que os deixaria fora de qualquer controle, mas do controle que se aproxima daquele existente nas comunicações transespecíficas, praticada pelos ameríndios, que mantém a consciência da representação inerente a qualquer tradução feita em um mundo repleto de possíveis referentes (Ibidem). Com isso, no contexto aqui analisado, realizar grandes eventos de saúde é criar um espaço para a comunicação e aparição de equívocos, os quais possibilitam o surgimento e fortalecimento das traduções negociadas.

Se voltarmo-nos para os dois casos que animam este artigo, é possível percebermos como a tradução negociada "autoridade e eficácia curativa do pajé” esteve presente na agência dos profissionais de saúde. É notável que os agentes saibam o que o pajé significa 
para o outro referente - que seria, principalmente, sinônimo de médico para os profissionais de saúde e mediador cosmopolítico para os xinguanos. Se concebermos que as pessoas não são entidades pré-estabelecidas que entram em relação, mas sim constituídas pelas relações que estabelecem (Strathern 2014), essa consciência da existência da concepção alheia sobre pajé passa a definir também essas pessoas quanto mais elas relacionam-se.

Assim é que os profissionais de saúde próximos ao Projeto Xingu que estão há mais tempo em relação com os xinguanos são afetados pelo tratamento do pajé e o respeitam, reproduzindo a tradução negociada mencionada sem constrangimento ou contradição pessoal. Traduzem, entretanto, para seus pares, a pajelança como uma forma de acalmar e tranquilizar as pessoas, e esta tradução - um pouco afastada daquela de que eu não curo, quem cura é o pajé - seria outra, fora do contexto de negociação política com os indígenas - como as outras traduções que os indígenas também fazem e que não são negociadas com os não indígenas, ou seja, que não são evidenciadas nas relações políticas.

\section{ALGUMAS CONSIDERAÇÕES}

Com base no que foi exposto, é possível considerarmos, sem pretensões conclusivas, as dificuldades presentes nas relações que corporificam a chamada atenção diferenciada que é buscada nas ações de saúde voltadas às populações indígenas. Ou seja, a "consideração das especificidades culturais, epidemiológicas e operacionais desses povos" (Brasil-PNASPI 2002: 6) não é algo que se faz de forma instintiva ou instantânea, mas é possível de ser negociada. No caso do baixo, médio e leste Xingu essa negociação gerou, em um momento histórico específico, a tradução "autoridade e eficácia curativa da medicina indígena", compartilhada nas relações com o Projeto Xingu ali engendradas.

Esperamos, a partir desses exemplos etnográficos, elucidarmos quão complexa é a história de interação entre profissionais de saúde não indígenas e diferentes povos indígenas, permeada por diferentes motivações, acúmulos e interesses dos agentes - indígenas, não indígenas e outros - na manutenção dessa relação em saúde, que não acontece descolada das demais relações locais e globais que a compõem (Balandier 1987), tais como as noções diferentes de autoridade, de corpo, de saúde/doença/cura, de prevenção, de agência, os diferentes entendimento sobra as políticas públicas de saúde aliadas à política indigenista nacional, sobre a formação biomédica e tantas outras dimensões possíveis de serem expostas e aprofundadas ao abordar este tema.

Haveria, assim, na execução das políticas públicas de saúde indígena em aldeia, não um compartilhamento de práticas de cura, mas sim intervenções biomédicas e agenciamentos outros - como pajés, raízes, cowvade etc. - em processos que possuem multidimensões na busca pela almejada cura. Há agentes com diferentes interesses, demonstrando poderes e negociando 
acordos. Há equívocos, mais possíveis de serem controlados conforme os outros referentes possíveis são conhecidos pelos agentes envolvidos. Há traduções negociadas de quem previne e quem cura, e outras. Seria importante para os estudos sobre saúde indígena que essas traduções também recebessem uma atenção diferenciada.

\section{NOTAS}

* Doutoranda do Programa de Pós-graduação em Antropologia social da Universidade Estadual de Campinas - karine.assumpcao@gmail.com.

${ }^{1}$ Ações baseadas em campanhas de saúde, também conhecidas como verticalizadas, cuja intervenção é pontual, diferente de ações mais horizontais, inseridas na rotina local, como são as Equipes Multidisciplinares de Saúde Indígena (EMSI) ou o médico da família, por exemplo. Saliento que o itálico será utilizado neste trabalho para termos e expressões dos sujeitos e aspas para termos a serem relativizados e citações de referências bibliográficas.

${ }^{2}$ Região centro-oeste do Brasil. Os povos mencionados neste trabalho estão todos nesta região. O povo Kawaiwete também é conhecido como Kaiabi.

${ }^{3}$ Detalho o programa adiante.

${ }^{4}$ Utilizarei aqui o termo genérico "pajé", que se tornou um termo corrente na antropologia ameríndia "para indicar os especialistas em conhecimentos médicos ou esotéricos" (Carneiro da Cunha 2009: 342). Porém, vale ressaltar que "a categoria genérica 'pajé' apaga uma série de distinções significativas que são importantes em quase todas as sociedades indígenas, pois é comum não haver em línguas indígenas uma palavra única que abranja os vários especialistas agrupados pelo termo "pajé". Ademais, faz-se importante ressaltar que o pajé/xamã não se restringe a um médico indígena, como podemos notar através dos estudos etnográficos sobre xamanismo na Amazônia (Gow 1994; Vilaça 2000). Utilizamos esta tradução neste trabalho sabendo ser apenas uma das dimensões possíveis.

${ }^{5}$ Secretaria criada após grande mobilização dos indígenas, indigenistas e sanitaristas para que a saúde indígena tivesse uma secretaria própria, vinculada diretamente ao Ministério da Saúde, e não mais a outros órgãos que cumpriam outras funções além da saúde das populações indígenas, como FUNAI e FUNASA.

${ }^{6}$ Para mais informações históricas sobre as políticas indigenistas no Brasil, ver: Ramos (1999), que explora o quadro da saúde indígena desde os etnocídios do início do contato até a criação do SPI; e Costa (1987), que analisa as intervenções de Rondon e Noel Nutels, a partir da década de 1950.

${ }^{7}$ As dezesseis etnias que vivem no Xingu: Aweti, Ikpeng, Kawaiwete, Kalapalo, Kamaiurá, Kisêdjê, Kuikuro, Matipu, Mehinako, Nahukuá, Naruvotu, Wauja, Tapayuna, Trumai, Yudja, Yawalapiti.

${ }^{8}$ Como, segundo o autor, o couvade não pode ser um termo generalizado, mas sempre analisado em seu contexto, ele apresentada as formas como os Waiwai e os Urubu realizam diferentes conjuntos de práticas de conhecimento que envolve cuidados na construção do corpo da criança e que envolvem os corpos dos pais.

${ }^{9}$ Sobre a eficácia simbólica do curandeiro, ver Levi-Strauss (2012).

${ }^{10}$ A utilização de qualquer medicina passa pela visão que os usuários possuem da doença/saúde e essa reflete, em grande parte, sua posição como membro de um grupo específico (Loyola 1991). 
${ }^{11}$ Coloco normalidade entre aspas para enfatizar que essa é uma graduação relativa, estando nesse caso de acordo com os preceitos biomédicos. Sobre o tema, ver Canguilhem (2009).

${ }^{12}$ Ressalto que essa reprodução não é isenta de transformações concomitantes. Durante a pesquisa notei diferenciações entre os profissionais de saúde que eram passíveis de serem relacionadas com o acúmulo de anos que atuavam no Xingu. Dediquei um capítulo da tese sobre esses afetos (Assumpção 2014).

${ }^{13}$ Sobre o primeiro movimento, ver Pereira (2012), Assumpção (2014) e Kelly (2015).

${ }^{14}$ Tradução não como arrumação, mas enquanto um remanejamento das ideias na percepção das relações (Carneiro da Cunha 1998).

${ }^{15}$ Regras ligadas a valores da sociedade ocidental, não de outras sociedades, não podendo ser classificado como "mentira" ou "charlatanismo" o ato do pajé curar várias vezes, por exemplo, uma pessoa com um quadro que os biomédicos considerariam episódios de "glicemia descompensada" de um diabético, logo, algo incurável. A cura em si é um conceito bastante polêmico que permeia as correntes que existem dentro da biomedicina. Para uma discussão sobre o conceito, ver Canguilhem (2009).

${ }^{16} \mathrm{E}$ cito esse exemplo aqui apenas para exemplificar o raciocínio, sem adentrar nessa discussão envolvendo religião e povos indígenas. Para uma discussão sobre o tema, ver Capiberibe (2007).

\section{REFERENCIAL BIBLIOGRÁFICO}

Assumpção, K. 2014. Negociando curas: um estudo das relações entre indígenas e profissionais do Projeto Xingu. Dissertação de Mestrado apresentada ao Programa de Pós-Graduação em Ciências Sociais da Universidade Federal de São Paulo, Brasil.

Baruzzi, R. G., e C. Junqueira. Organizadores. 2005. Parque Indígena do Xingu. Saúde, Cultura e História. São Paulo: Terra Virgem.

Brasil. Fundação Nacional de Saúde. 2002. Política Nacional de Atenção a Saúde dos Povos Indígenas. Brasília: Ministério da Saúde, Fundação Nacional de Saúde.

Buchillet, D. 2002. Contas de vidro, enfeites de branco e "potes de malária", in Pacificando o branco: cosmologias do contato no Norte-Amazônico. Organizado por B Albert e A. R. Ramos. São Paulo: Editora UNESP.

Campos, G. W. de S. 1997. A clínica do sujeito: por uma clínica reformulada e ampliada. Disponível em: <http://www.pucsp.br/ prosaude/downloads/bibliografia/CLINICAampliada.pdf.> Acesso em: 27 dez. 2017.

Canguilhem, G. 2009. O normale o patológico. Rio de Janeiro: Forense Universitária

Capiberibe, A. 2007. Batismo de fogo: os Palikur e o cristianismo. São Paulo: Annablume; FAPESP; Nuti.

Cardoso, M. 2004. Políticas de saúde indígena e relações organizacionais de poder: reflexões decorrentes do caso do Alto-Xingu, in Saúde dos povos indígenas: reflexões sobre antropologia participativa. Organizado por E. Langdon e L. Garnelo. Rio de Janeiro: Contra Capa

. 2015. Políticas de saúde indígena no Brasil: do modelo assistencial à representação política, in Saúde Indígena: politicas comparadas na América Latina. Organizado por E. Langdon e M. Cardoso. Florianópolis: UFSC.

Carneiro da Cunha, M. C. 1998. Pontos de vista sobre a floresta amazônica: xamanismo e tradução. Mana, v.4, n.1: 7-22 
2009. "Cultura" e cultura: conhecimentos tradicionais e direitos intelectuais, in Cultura com aspas. São Paulo: Cosac Naify

Costa, D. C. 1987. Política Indigenista e assistência à saúde Noel Nutels e o Serviço de Unidades Sanitárias Aéreas. Cadernos de saúde pública, 4(3), 388-401

Diehl, E. e N. Rech. 2004. Subsídios para uma assistência farmacêutica no contexto da atenção à saúde indígena: contribuições da antropologia, in Saúde dos povos indígenas: reflexões sobre antropologia participativa. Organizado por E. Langdon e L. Garnelo. Rio de Janeiro: Contra Capa

Duarte, L. F. 2003. Indivíduo e pessoa na experiência da saúde e da doença. Revista Ciência \& Saúde coletiva, 8(1): 173-183

Franco Neto, J. V. 2010. Xamanismo Kalapalo e Assistência Médica no Alto Xingu: estudo etnográfico das práticas curativas. Dissertação de Mestrado, Departamento de Antropologia da Universidade Estadual de Campinas, IFCH/UNICAMP, São Paulo, Brasil.

Foller, M-L. 2004. Intermedicalidade: a zona de contato criada por povos indígenas e profissionais de saúde, in Saúde dos povos indígenas: reflexões sobre antropologia participativa. Organizado por E. Langdon e L. Garnelo. Rio de Janeiro: Contra Capa

Gallois, D. T. 1991. A categoria "doença de branco": ruptura ou adaptação de um modelo etiológico indígena?, in Medicinas tradicionais e medicina ocidental na Amazônia. Organizado por D. Buchillet. Belém: MPEG/ Edições Cejup, UEP.

Garnelo, L. e S. Sampaio. 2003. Bases sócio-culturais do controle social em saúde indígena. Problemas e questões na Região Norte do Brasil. Cad. Saúde Pública, 19(1): 311-317.
Grünberg, G. 2004. O Kaiabi do Brasil Central: história e etnografia. São Paulo: Instituto Socioambiental

Gow, P. 1994. River people: shamanism and history in Western Amazonia, in Shamanism, bistory and the state. Editado por $\mathrm{N}$. Thomas \& C. Humphrey. Ann Arbor: The University of Michigan Press

Junqueira, C. 2005. Pajés e feiticeiros, in Parque Nacional do Xingu: saúde, cultura e história. Organizado por R. Baruzzi e C. Junqueira. São Paulo: Terra Virgem.

Kelly, J. A. 2009. "Os Encontros de Saberes”: equívocos entre índios e Estado em torno das políticas de saúde indígena na Venezuela. ILHA, vol. 11, n. 2: 265-302.

. 2015. Uma etnografia de ponta a ponta: o Ministério da Saúde e os Yanomami do Amazonas, Venezuela, in Saúde Indígena: políticas comparadas na América Latina. Organizado por E. Langdon e M. Cardoso. Florianópolis: UFSC.

Kopenawa, D. e B. Albert. 2015. A queda do céu: palavras de um xamã yanomami. São Paulo: Companhia das letras.

Langdon, E. J. 1988. Saúde indígena: a lógica do processo de tratamento. Revista de Saúde em Debate, Centro Brasileiro de Estudos de Saúde.

2005. A construção sociocultural da doença e seu desafio para a prática médica, in Parque Nacional do Xingu: saúde, cultura e história. Organizado por R. Baruzzi e C. Junqueira. São Paulo: Terra Virgem.

Laplantine, F. 1986. A doença e o sagrado, a medicina e a religião, a cura e a salvação: da antropologia médica à antropologia religiosa, in Antropologia da Doença. São Paulo: Martins Fontes

Laurell, A. C. 1982. A saúde-doença como processo social. Revista Latinoamericana de Salud, México, 2: 7-25. 
Le Breton, D. 2011. Medicina e medicinas: de uma concepção do corpo a concepções do homem, in Antropologia do corpo e modernidade. Petrópolis: Vozes.

Lévi-Strauss, C. 1993. Introdução, in História de lince. São Paulo: Companhia das Letras.

2012. O feiticeiro e sua magia/ A eficácia simbólica, in Antropologia estrutural I. São Paulo: Cosac Naify

Lima, T.S. 2005. Um peixe olhou para mim: o povo Yudjá e a perspectiva. São Paulo: Ed. UNESP: ISA; Rio de Janeiro: NuTI.

Loyola, M. A. 1991. Medicina tradicional e medicinas alternativas: representtações sobre a saúde e a doença, concepção e uso do corpo. in Medicinas tradicionais e medicina ocidental na Amazônia. Organizado por D. Buchillet. Belém: MPEG/ Edições Cejup, UEP.

Mauss, M. 1973. Uma categoria do espírito humano: a noção de pessoa, a de "eu", in Sociologia e antropologia. São Paulo: Cosac Naify

Pereira, P.P.G. 2012. Limites, traduções e afetos: profissionais de saúde em contextos indígenas. Mana 18(3): 511-538.

Projeto Xingu, Unidade de Saúde e Meio Ambiente, Departamento de Medicina Preventiva, Universidade Federal de São Paulo/UNIFESP. 2009. Relatório do convênio - UNIFESP/FUNASA. São Paulo.

Projeto Xingu. Unidade de Saúde e Meio Ambiente, Departamento de Medicina Preventiva, Universidade Federal de São Paulo/UNIFESP. 2013. Proposta para Oficina de Culinária - Povo Kawaiweté - Aldeia Guarujá e convidados: Pesquisa-ação sobre Transição Epidemiológica e Nutricional entre os Kawaiwete do DSEI Xingu/MT.

Rivière, P. G. 1974. The Couvade: A Problem Reborn. Man 9: 423-435
Seeger, A. 1980. Os indios e nós: estudos sobre sociedades tribais brasileiras. Rio de Janeiro: Campus.

Seeger A., R. Da Matta, E. Viveiros de Castro. 1979. A construção da pessoa nas sociedades indígenas brasileiras, in Boletim do Museu Nacional. Rio de Janeiro: UFRJ.

Silveira, N. H. 2004. O conceito de atenção diferenciada e sua aplicação entre os Yanomami, in Saúde dos povos indígenas: reflexões sobre antropologia participativa. Organizado por E. Langdon e L. Garnelo. Rio de Janeiro: Contra Capa.

Ramos, A. R. 1999. Projetos Indigenistas no Brasil Independente, in Série Antropologia 267. Brasília: DAN/UnB.

Strathern, M. 2006. O gênero da dádiva: problemas com as mulheres e problemas com a sociedade na melanésia. Campinas: UNICAMP.

. 2014. "Sem natureza, sem cultura: o caso Hagen", "A relação: acerca da complexidade e da escala" e "O efeito etnográfico", in O efeito etnográfico. São Paulo: Cosac Naify, 2014.

Tavares, F. 2017. Rediscutindo conceitos na antropologia da saúde: Notas sobre os agenciamentos terapêuticos. Mana 23(1): 201-228. Verani, C. B L. 1990. A "doença da reclusão" no Alto Xingu: Estudo de um Caso de Confronto Cultural. Dissertação de Mestrado apresentada ao Programa de Pós-Graduação em Antropologia Social do Museu Nacional da Universidade Federal do Rio de Janeiro, Brasil.

Vilaça, A. 2000. O que significa tornar-se outro? Xamanismo e contato interétnico na Amazônia. Revista Brasileira de Ciências Sociais, 15(44): 56-72.

Viveiros de Castro, E. 2004. Perspectival Anthropology and the Method of Controlled Equivocation. Tipití 2(1):3-22. 